\section{Biglycan meets utrophin}

\section{By Tim Fulmer, Senior Writer}

Brown University researchers have found that systemic delivery of biglycan, an extracellular matrix glycoprotein, decreases muscle pathology and improves muscle function in dystrophic mice. ${ }^{1}$ The findings have been licensed to Tivorsan Pharmaceuticals Inc., which is working with the Brown team to optimize recombinant biglycan for delivery to patients with Duchenne muscular dystrophy.

Previous work in mice by Justin Fallon and colleagues at Brown showed that biglycan (BGN) is abundant in regenerating muscle ${ }^{2,3}$ and helps regulate expression of multiple components of the dystrophinassociated protein complex (DAPC). ${ }^{4-6}$ In muscular dystrophy patients, mutations in the dystrophin protein disrupt the function of the DAPC, leading to severe muscle pathology and loss of muscle function.

Based on those findings, Fallon's group hypothesized that biglycan could increase DAPC function in muscular dystrophy. Fallon, a professor of neuroscience at Brown, cofounded Tivorsan in 2008.

To test that hypothesis, the researchers first looked at biglycan knockout mice to see whether loss of biglycan influenced levels of utrophin, a protein expressed in developing muscle that is highly homologous to dystrophin and known to interact with the DAPC. Animal data have suggested that raising utrophin levels in the absence of dystrophin could have a disease-modifying effect in muscular dystrophy. ${ }^{7-9}$

Indeed, muscle tissue from biglycan knockout mice had significantly lower levels of utrophin than muscle tissue from wild-type mice $(p<0.0001)$. Moreover, the addition of recombinant biglycan to cultured mouse muscle cells deficient in the protein led to upregulation of utrophin at the cell membrane. Thus, biglycan directly increased the activity of utrophin.

Fallon's team next delivered a recombinant form of biglycan to $d y$ strophin ( $d m d ; m d x)$ knockout mice, the standard mouse model of muscular dystrophy.

In the animals, a single systemic dose of biglycan significantly lowered muscle pathology and increased muscle function compared with vehicle control ( $p=0.028$ and $p=0.02$, respectively). The treatment was not associated with organ toxicity.

The findings, which were published in the Proceedings of the National Academy of Sciences, are covered by Brown University patents.
According to Joel Braunstein, CEO and cofounder of Tivorsan, the company is working with Fallon's lab "doing whatever further optimization is necessary, as well as setting up the required bioassays, toxicology and pharmacokinetic studies, in order to file an IND with the FDA as soon as possible."

\section{Upping utrophin}

Fallon said recombinant biglycan meets many of the criteria for a strong muscular dystrophy therapeutic.

"First of all, biglycan doesn't require direct injection into the muscle but can be delivered systemically and still show significant activity in diseased muscle without appearing detrimental to other organs," he noted. "Secondly, although most endogenous biglycan is a proteoglycan and therefore has glycosaminoglycan side chains, it unexpectedly turns out that the recombinant form is biologically active even without those carbohydrate modifications. That should greatly simplify and reduce the cost of large-scale manufacture of the compound."

Finally, he said, "as a strategy that increases levels at the muscle cell membrane, biglycan should be complementary to other potential muscular dystrophy therapies, such as exon skipping and agents aimed at increasing muscle mass."

For example, an exon-skipping therapy could increase muscle levels of dystrophin in parallel with utrophin-enhancing biglycan therapy.

"Compared with dystrophin gene therapy, utrophin-based therapies have a reduced likelihood of triggering an unwanted immune reaction. That's because muscular dystrophy patients continue to express utrophin, albeit at very low levels, and are thus less likely to see the delivered protein as foreign, much as they might for dystrophin," said James Ervasti, professor of biochemistry, molecular biology and biophysics at the University of Minnesota.

"Compared with exon-skipping therapies, which correct mutations in the dystrophin gene, a utrophin-based therapy is presumably not limited to patients that express a particular dystrophin mutation," Ervasti added. "The reason is utrophin can potentially replace dystrophin and perform its function regardless of the mutation that rendered dystrophin nonfunctional."

Ervasti and colleagues have developed and patented a strategy for delivering a functional form of utrophin to muscle cells using a fragment of the HIV tat protein. In $m d x$ mice, the tat-utrophin fusion construct decreased muscle pathology and increased muscle performance. ${ }^{10}$

At this point there are not enough data to compare the utrophin-enhancing biglycan strategy and the tat-based utrophin approach.

Kay Davies, professor of anatomy at the University of Oxford and honorary director of the Medical Research Council functional genetics unit, also expects that utrophin-based therapies should have a good safety profile. "Some of our research in mice has shown that even if utrophin levels are increased in most of the body's organs, we do not get 


\section{ANALYSIS}

a toxic effect," suggesting there is less likelihood of toxicity problems with delivering too much utrophin to patients, said Davies.

Davies was the first researcher to show that utrophin is structurally homologous to dystrophin and that upregulation of the former can compensate for deficiencies in the latter. ${ }^{11,12}$

Thus far, the clinical experience with enhancing utrophin has been both limited and unsuccessful. In 2010, after completion of a Phase I trial, BioMarin Pharmaceutical Inc. and Summit Corp. plc ended their agreement when BioMarin discontinued further development of SMT C1100, an orally available small molecule upregulator of utrophin mRNA.

At that time, BioMarin said the doses used in the trial had failed to achieve the plasma concentrations necessary to increase utrophin expression in target tissues. However, Summit stated that an "appropriate formulation" could allow clinical development of the compound to continue.

BioMarin has returned full rights of SMT C1100 to Summit, "who want to find another partner and begin a new Phase I trial based on reported data that showed the plasma levels of $\mathrm{C} 1100$ were close to what Summit researchers believe is needed to increase utrophin RNA levels for a therapeutic effect," said Jon Tinsley, senior director of R\&D at Summit.

Tinsley told SciBX that by increasing transcription of the utrophin gene in all muscle cells, "SMT C1100 is designed to increase the longevity of muscle fibers whether or not those fibers still express low levels of utrophin in the muscular dystrophy patient." In that regard, he said,
SMT C1100 could offer advantages over biglycan, "which seems to work mainly by stabilizing utrophin in that subset of muscle cells that still have residual utrophin activity," he said.

Fulmer, T. SciBX 4(5); doi:10.1038/scibx.2011.122

Published online Feb. 3, 2011

\section{REFERENCES}

1. Amenta, A.R. et al. Proc. Natl. Acad. Sci. USA; published online Dec. 27, 2010; doi:10.1073/pnas.1013067108 Contact: Justin R. Fallon, Brown University, Providence, R.I. e-mail: Justin_Fallon@brown.edu

2. Casar, J.C. et al. Dev. Biol. 268, 358-371 (2004)

3. Lechner, B.E. et al. Muscle Nerve 34, 347-355 (2006)

4. Bowe, M.A. et al. J. Cell Biol. 148, 801-810 (2000)

5. Rafii, M.S. et al. J. Cell Physiol. 209, 439-447 (2006)

6. Mercado, M.L. et al. FASEB J. 20, 1724-1726 (2006)

7. Ebihara, S. et al. Physiol. Genomics 3, 133-144 (2000)

8. Cerletti, M. et al. Gene Ther. 10, 750-757 (2003)

9. Tinsley, J. et al. Nat. Med. 4, 1441-1444 (1998)

10. Sonnemann, K.J. et al. PLoS Med. 6, e1000083; published online May 26, 2009; doi:10.1371/journal.pmed.1000083

11. Tinsley, J.M. et al. Nature 384, 349-353 (1996)

12. Tinsley, J.M. \& Davies, K.E. Neuromuscl. Disord. 3, 537-539 (1993)

\section{COMPANIES AND INSTITUTIONS MENTIONED}

BioMarin Pharmaceutical Inc. (NASDAQ:BMRN), Novato, Calif. Brown University, Providence, R.I.

Medical Research Council, London, U.K.

Summit Corp. plc (LSE:SUMM), Abingdon, U.K. Tivorsan Pharmaceuticals Inc., Providence, R.I. University of Minnesota, Minneapolis, Minn. University of Oxford, Oxford, U.K. 